\title{
Hitting the target
}

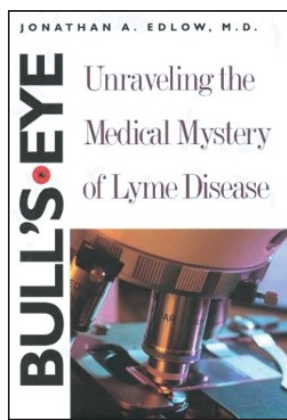

In Bull's-Eye: Unraveling the Mystery of Lyme Disease, author Jonathan Edlow has engagingly blended two narratives: a history of Lyme disease and a lay audience-oriented description of the disease and its management. Included almost as sidebars are informative but optional explanations of medical matters, such as how ELISA works, and entertaining historical vignettes, such as the treatment of syphilis by what was called 'malariatherapy'.

The two themes are woven together-usually deftly, but sometimes awkwardly-in covering the polarization of groups with different views, which the author carefully terms "conventional" and "alternative," about what Lyme disease is, how to diagnose it and how to treat it. A disclosure: Edlow includes me in the book and recommends my book on Lyme disease. I have been a witness and participant since the initial isolation of the disease agent, Borrelia burgdorferi. Most Internet postings and chatter have assigned me to the conventional camp, rather than the alternative.

The strongest and most durable aspect of the book, but also the one least likely to inspire the publisher's marketing department, is the history of Lyme disease. Edlow comprehensively but succinctly covers the earliest recognition of Lyme disease under a couple of other names a century ago in Europe, the fits and starts in the search for its etiology, the progress - and lack thereof-in the diagnosis and treatment of the disorder and, finally, the appearance and recent abrupt disappearance from the market of the human vaccine.

Through extensive research of print sources and a series of interviews over a decade, Edlow has provided mostly contemporary and first-hand accounts of the events, often by the key people involved. One could quibble about some of the facts and the allocation here and there of priority, but for the most part the history is balanced.

Edlow's account also gives appropriate credit to some physicians in Europe and the United States who participated in the investigation of the mystery, but who are now cited less prominently than others. This and other historical aspects of the book, which make up the majority of the text, will be of interest to general readers as well as to health-care workers, microbiologists and epidemiologists. The book should be

Alan Barbour is professor of medicine and microbiology \& molecular genetics at University of California, Irvine, Medical Sciences I, Irvine, California 926974025, USA

e-mail: abarbour@uci.edu considered essential for medical libraries and other repositories of the history of medicine.

The other narrative in the book is directed more toward the general public and patients than to physicians and other health-care workers. Readers will learn about Lyme disease and its cause, diagnosis and treatment in sections interspersed throughout the story of its discovery and elucidation. Edlow includes a helpful, jargon-free discussion about medical decision-making and patiently explains the vagaries of diagnostic tests and their interpretation. Twenty or thirty years from now, the details in the book on what is current diagnosis and therapy may get less attention than the history itself, but for now the book provides both a history and an accessible medical reference in an entertaining package.

Less successful is the attempt to invest the controversy about Lyme disease with more grandeur than it probably deserves. References to Thomas Kuhn and paradigm shifts, and analogies to Ptolemy and Copernicus, may be flattering to those on either side of the dispute, but they are unjustified. One does not frequently hear of Kuhn being invoked in discussions about alien abduction or other phenomena that are difficult to document. The fact is that there are perhaps a few hundred to a few thousand people who are convinced they have Lyme disease, even in the absence of many of the traditionally accepted indicators of infection. These individuals hold the alternative view of the disease. From their point of view, there is a cabal of mostly academic and government physicians, abetted by insurance companies and vaccine makers, who do not take their illnesses seriously enough.

The conventional view is that Lyme disease may sometimes be difficult to diagnose and may require prolonged therapy, but it usually does not. From the conventional viewpoint, Lyme disease is not fundamentally different from most other infectious diseases, and there is little or no rationale to broaden its current definition-infection with $B$. burgdorferi.

Individuals holding the alternative view turn for relief to some physicians who make or support the diagnosis and treat them, often with lengthy antibiotic regimens that third parties will not pay for in full.

Nevertheless, at least one disorder in the southeastern United Stateswhich resembles Lyme disease but is not caused by B. burgdorferibecame hidden by accusations of over-diagnosis on one side and conspiracy on the other. Edlow effectively describes the persistent efforts by Ed Masters, a family physician in Missouri, and others to bring this clinical syndrome to health authorities' attention. It remains to be determined how serious and extensive a medical threat 'Masters' disease' really is. But the initial reluctance of government and professional medical organizations to pay attention to the message, albeit poorly articulated, has fueled the distrust and amplified the contention that Lyme disease is more rampant than official statistics indicate.

One of the lessons from Edlow's saga of the disorder, then, is that when someone cries 'wolf' by claiming a case of Lyme disease, they may indeed not be infected with B. burgdorferi. But, to extend the analogy, there may still be a fox, or a disorder that looks like Lyme disease in some aspects, but is caused by something else. As the author seems to suggest, those of us accustomed to false alarms in this situation should not completely tune out. 